\title{
A probability-based multiscale model to quantify the impact of hydropeaking on mesohabitat suitability in rivers
}

\author{
Bähar Jelovica ${ }^{1}$, Hannu Marttila ${ }^{1}$, Faisal Bin Ashraf ${ }^{1}$, Björn Klöve ${ }^{1}$, and Ali Torabi \\ Haghighi $^{1}$
}

${ }^{1}$ Water Energy and Environmental Engineering Research Unit University of Oulu Finland

December 30, 2021

\begin{abstract}
One of the negative effects of hydropower on river environment includes rapid changes in flow and habitat conditions. Any sudden flow change could force fish to move towards a refuge area in a short period of time, causing serious disturbances in the life cycle of the fish. A probability-based multiscale model was developed to quantify the impact of hydropeaking on habitat suitability for two fish species. The model used habitat preference curves, river flow and depth to develop the suitability maps. The suitability index maps reveal that habitat suitability deteriorates as flow increases in this part of the river. The probability model showed that, on average, suitability indices are higher for adult grayling than juvenile trout in hydropeaking events in the studied area. In addition, the life stages of fish determine their response to the sudden flow change. The method developed shows the potential to be used in river management and the evaluation of hydropeaking impacts in river systems affected by hydropower.
\end{abstract}

Hosted file

Manuscript - Special Issue in Hydropeaking Research.docx available at https://authorea. com/users/453050/articles/550987-a-probability-based-multiscale-model-to-quantify-the-

impact-of-hydropeaking-on-mesohabitat-suitability-in-rivers 